\title{
Intercultural competences of students-strategic approaches
}

\author{
Daniel Mara*,1 \\ ${ }^{1}$ University "Lucian Blaga" of Sibiu, Department of Teacher Training, Calea Dumbrăvii 34, Sibiu, \\ Romania,
}

\begin{abstract}
Intercultural education is a category of the "new education” and a desideratum of the European dimension of education. This study presents the results obtained from a research centred on the training and development of intercultural skills of students of "Lucian Blaga” University of Sibiu which are enrolled in various study programmes of the Socio-Human Sciences Faculty. The study was based on the general hypothesis that teaching in higher education in an intercultural context contributes to the formation and development of intercultural skills in students, as well as improving and streamlining the learning process, increasing interest in the cultural characteristics of other peoples. The research method used diagnose the intercultural component of the sociohuman sciences curriculum, was the survey method and the tool used on identifying students' intercultural competencies was a questionnaire. Intercultural skills of students can be formed by teachers, who in turn have such skills and capitalize them in educational and professional contexts, so that teaching becomes a living laboratory in which democratic values are promoted based on acceptance of otherness, respect for other cultures and the confidence in the potential of every human being. Students with intercultural skills can contribute to the sustainability of a future society since they can integrate socially, culturally professionally without high costs and financial investments.
\end{abstract}

\section{Introduction}

Intercultural education is a category of the „new education” and a desideratum of the European dimension of education. The evolutional process of the concept has led to the inclusion of the intercultural education in the phrase ,education for all”, being defined in the spirit of education paradigm for cultural diversity.

Intercultural education involves an ,inclusive teaching-learning process, which involves all students in consolidating a strong sense of self-confidence, strengthening empathic perceptions of people from different cultural backgrounds and promoting equal opportunities to reach their full potential" [1].

\footnotetext{
* Corresponding author: daniel.mara@,ulbsibiu.ro
} 
Intercultural education is an integrative concept [2], and the application of its principles implies, at the same time, respect for diversity and equity, by offering an equal importance to the possibilities offered to each cultural group, to maintain, develop and affirm publicly its own identity, as well as communication, contacts and cultural exchanges, which require knowledge, understanding and mutual respect of people with different cultural backgrounds. The development of intercultural competences is also achieved in order to affirm social performance in the field of social inclusion, both for people at the risk of social exclusion or marginalized groups, and for all of those who are part of multicultural communities, due to the fact that inclusion capitalizes on diversity and differences [3].

The principles, objectives, contents and means of achieving intercultural education are defined in the spirit of the values of interculturalism and affirmed at legislative, institutional, and curricular level [4]. The values of interculturalism are part of the key values of the European consciousness: respect for human rights, tolerance, cultural traditions, social justice, solidarity, promotion of social inclusion.

An educational institution anchored in the dynamics of change in today's society is oriented by a strategic plan that ensures the process of adaptation, orientation and maintenance or increase of the quality level of the educational process.

At the faculty level, the existing strategic internationalization plan at the university level was transposed, which is a major direction of action, which aims both to increase the prestige and visibility of the institution, and to attract human and financial resources.

The objectives at internationalization level aim at:

- consolidating and institutionalizing the partnerships with similar groups of some higher education institutions from abroad, in order to organize master programs in interuniversity cooperation, as well as to increase the degree of integration in international research networks etc.;

- attracting researchers and teachers from other universities in the international space for teaching or research activities;

- $\quad$ increasing the number of publications at international publishing houses;

- increasing the degree of involvement, the visibility of the holders within the international professional associations, in the fields of activity of the departments;

- development of the Erasmus + Program for all specializations in terms of student and teachers mobility;

- the application of the placement program for the specialized practice, as a viable measure in terms of increasing the practical skills of our students and master's student.

- $\quad$ initiating and developing research partnerships and implementing projects with foreign partners;

- development and consolidation of doctoral programs organized in collaboration with prestigious universities in Europe or world.

\section{Material and Methods}

\subsection{Students' intercultural competences}

The fundamental objective of an intercultural oriented education is the training of intercultural skills of pupils and students [5]. The concept of intercultural competences refers to a set of skills, aptitudes, behaviours and knowledge, which applied wittingly and in harmony with the intercultural environment, create the premises for a neat solution to various situations of intercultural interaction. Intercultural competence allows finding 
effective solutions to problems in intercultural contexts. Intercultural competence includes the following components: cognitive, affective and behavioural.

Creativity is also included in the process of developing this set of skills. The lack of creativity totally impairs human evolution. In other words, is the catharsis that drives evolution. It can be influenced by one's practices and environment [6].

The cognitive component presupposes the existence of adequate cultural and intercultural awareness. This component involves recognizing that people interpret one and the same behaviour in different ways. The affective component includes a set of attitudes of esteem and recognition, openness, appreciation, respect, curiosity towards the other. The behavioural and communication component implies the ability to empathize, to tolerate the presence of the other, to find and use effective ways of adaptation in situations of intercultural interaction.

Intercultural competences favour the establishment and development of intercultural relations. The intercultural relationship aims at the collaboration between the representatives of two or more cultures and consists in capitalizing the knowledge, capacities, abilities, attitudes of those involved, in order to favour the communication, understanding, transfer of information between them [7].

The study's activities at a bachelor's or master's programme intents to train and develop specialized, professional competences of students that allow them later, to carry out an activity in that field. In addition to these professional skills, students will also develop other equally important and necessary skills, many of which are transversal, skills that allow students to cope with situations aimed at effective integration in different contexts of life and professional skills, communication, intercultural, elaboration and implementation of projects, entrepreneurship etc. Students' intercultural competences can be acquired in activities carried out in the formal, non-formal and informal educational environment.

All curricular and extracurricular activities with intercultural content carried out within the faculty included teaching strategies based on collaborative learning, teamwork, projects, and practical work. The formation of intercultural competencies is achieved through collaborative teaching strategies, which involve the positive interdependence of students, the establishment of common goals, common resources, and distinct roles. An important step in the evolution of intercultural skills is interpersonal communication, the formation of cooperation skills with others. In such educational context, training and education activities with intercultural content can be carried out.

\subsubsection{Trained and developed competences in the formal educational environment}

The formal educational environment consisting of instructive-educational activities carried out in the university represents a favourable framework for the achievement of some capacities by the students that would constitute the fundamental elements of the intercultural competence. Cultural diversity is a resource for developing students' skills [8]. It aims at students' cognitive and metacognitive development by training the capacity to:

- cooperate with colleagues to solve the received tasks;

- build together with other students a common behavioural code, regarding their reactions in situations of beliefs, norms, principles, values, divergences of opinions;

- be aware of the characteristics of one's own person, characteristics derived from the cultural environment and to capitalize them in appropriate contexts;

- $\quad$ observe and evaluate the colleagues' behaviour to comparatively report to them;

- $\quad$ establish certain landmarks (personality models, symbolic elements) and to follow them during one's own evolution;

- $\quad$ adapt and integrate in a collective, in intercultural environments; 
- $\quad$ find effective solutions for intercultural harmonization;

- $\quad$ analyse and evaluate the implications on intercultural communication;

- work in teams in a national or international intercultural environment (projects, internships, study mobility etc.);

- manage and adequately fulfil one's professional attributions in a future intercultural professional framework (multicultural companies, national or international intercultural organizations and institutions etc.).

All these skills, components of intercultural competence accomplished by students, offer them the opportunity to approach constructively different educational contexts, solve problems, which overreached the boundaries of a specific academic learning and ensure the transfer of the learning outcomes in one's own life and professional experiences.

\subsubsection{Trained and developed competences in the non-formal educational environment}

The activities carried out outside the university curricula offer students multiple opportunities to participating in intercultural events and actions. Activities organized for leisure (trips, visits, camps, exhibitions, shows, conferences, round tables, festivals, competitions), as well as activities carried out in the socio-professional environment (internships, Erasmus + mobility at partner universities, etc.) contribute to the development of student's ability to:

- organize non-formal intercultural activities;

- establish and maintain friendships, intercultural contacts;

- explore and investigate some cultural environments;

- mediate and resolve possible intercultural conflicts;

- apply certain knowledge (foreign languages, geography, informatics, history, etc.) in intercultural situations;

- participate in intercultural actions organized by various associations, foundations, institutions specialized in this field;

- develop and adaptation of one's scientific level and professional training in relation to an intercultural space.

Non-formal education creates many opportunities for both personal and professional development of students, completes and consolidates what they have accumulated in the formal university environment.

\subsubsection{Trained and developed competences in the informal educational environment}

The informal educational environment, which includes all influences exerted on the student at the level of family, locality, community, group of friends and media offers various ways of forming intercultural skills. Students can develop skills to:

- relate with other students who come from different cultural backgrounds and with their families;

- get involved in cultural, religious actions, carried out in the community from which they are part of;

- $\quad$ watch and listen to intercultural programs broadcast on television and radio;

- read materials, books, magazines, newspapers, brochures, dealing with intercultural topics or different cultures;

- access, through the Internet, sites containing materials, programs, intercultural projects; 
- contribute through ideas and actions in the public sphere to the formation of a civil society that is based on mutual respect of each other's values;

Informal education activities are very important the self-instruction and self-education competences of students which allows them a process of selection, organization, planning of such activities. Without a well-planned and a balanced approach, especially from the time management point of view, these activities may have less beneficial effects for young people.

\subsection{Intercultural University Education}

Although intercultural education initially appeared as a possible solution to different difficulties which encountered in the process of schooling children, young immigrants, over time, it has far exceeded this scope of that respective context. It has now become clear that intercultural education is not a compensatory education for foreigners, is not a new subject and does not identify with the language and cultural courses for immigrants [9].

The statement according to which intercultural education is not a compensatory education for foreigners, is based on concrete research date, which has shown that in multicultural societies, educational problems are not of immigrant students who cannot adapt to new cultural realities, but of the educational institutions that prove themselves too little capable to adapt to cultural diversity and to provide students with adequate learning support of the language and culture of the country of adoption [10].

Intercultural education is not a new school subject, because, as stated by the authors cited above, professors who practice an intercultural pedagogy will promote, in all subjects, an open attitude, oriented towards valuing cultural differences, avoiding stereotypes and will value the presence of students which come from different cultures. Furthermore, highlighting their culture of origin in the context of the culture of adoption and to make others aware of all what cultural diversity means and represents [11].

Intercultural education according to the same authors shouldn't be confused with the language and culture courses of the origin of students belonging to minority communities because their simple promotion, even if it ensures the preservation of the cultural identity of those communities, does not lead to the necessary permeabilization of borders which separate the culture of majority from the minority communities' culture.

Intercultural education includes in its structure several interconnected dimensions: the intercultural movement, the intercultural curricula, the intercultural instructive-formative process and, finally, the intercultural commitment [12].

The intercultural movement is focused on ensuring equal educational opportunities and equity between various socio-cultural groups, aiming at incorporating and capitalizing on existing cultural diversity through education, without the meaning of diminishing the attention paid to the culture of the majority or lowering the schools' academic excellence standards as an institution.

The intercultural curricula involve capitalizing through the instructive-formative conveyed contents, which take into consideration all the assets and differences that make these communities unique. Furthermore, its role in the processes of evolution towards an intercultural society and cultural adoption is of high importance.

The process of intercultural education refers to the use of various instructive-formative situations to develop students' ability to understand different cultures, to accept and appreciate the differences that occur between individuals belonging to different cultural communities. The differences, but also the similarities among various cultures should be presented to in such a manner that it will lead him/her to the appearance of the possibility of an intercultural authentic dialogue. 
Intercultural engagement aims at the constant transposition of intercultural philosophy into a context-aware cultural behaviour. By simply knowing the principles and the law that guide interculturalism, although important, but that is not enough in terms of correct relations between a majoritarian community and a minor one, no matter its type, even if we refer to them from the cultural or religious, to ethnic or racial point of view. In this way, an education towards intercultural awareness should provide enough real-life experiences engagement of students, in order to sensitize them of the cultural differences that exist in various societies.

In essence, the approaches subsumed to the intercultural education aim at establishing equitable relations, based on the values of democracy, between the majority and diverse minority communities, aiming at eliminating negative phenomena of stereotype labelling, marginalization or discrimination. From this perspective, professors accompany students in the proper understanding of the concept of discrimination. Moreover, they need to make sure that the negative impact of discriminatory behaviour is well understood. The literature considers discrimination as being a favourable treatment (positive discrimination) or unfavourable (negative discrimination) of a category of people, an attitude that is not related to those objective characteristics or real activity.

The origin of discriminatory behaviour is related to the subjective point of view of the discriminator, which is usually accompanied by a distorted perception of the reality. Moreover, the mere existence of certain stereotypes also leads to discriminatory acts. Stereotypes, in general, are defined as impermissible generalizations of certain experiences, by means of the collective representations of the affiliation group, thereby producing a bag of positive or negative characteristics of a particular cultural community. Furthermore, the prejudices thus gathered are relatively constant in time. Concrete experiences encountered in daily life, that may contradict these prejudices, harshly have an impact. Thereby, the party will be responsive just to those aspects or manifestations which are according to its personal judgement or already assumed stereotype.

Closely related to the existence of prejudices, negative discrimination can take different forms, oscillating between passive avoidance, negative verbalization and active discrimination that can degenerate into acts of violence. Regardless of the form in which it occurs, discrimination is a negative phenomenon and invariably has the consequence of marginalizing a certain community or an entire segment of society.

Intercultural education in university will focus, from this perspective, on supporting students in their awareness of the mechanisms that lead to stereotypes and prejudices. Hands-on demonstrations which expose the lack of certain prejudices and which are fostering the development of positive attitudes in this matter are good practices.

The range of possible strategies and methods available for a teacher which prepares an intercultural pedagogical course is quite vast, including elements such as:

- enriching the courses with information about the unique aspects of the history and culture of the different communities, insisting on their dimensions of convergence;

- the use of comparisons in the description and analysis of different cultures, thus enabling students to knowingly realize and retain the different aspects of these cultures;

- presentation of some remarkable personalities from the national or international cultures;

- promoting positive interpersonal relationships between students and people with various cultural background;

- engaging students to proactively take part into a discussion about the problems which arouse in the relations among different cultures and to make some conclusions to better understand these cultures and be able to alleviate any divergences; 
- educative valorisation of the resources of their own community (by studying the approaches and changes made by various personalities throughout history and the evolution of the respective community);

- supporting students in understanding the process of genesis of stereotypes and cultivating personal pride for belonging to a certain culture, simultaneously developing respect for other cultures;

- $\quad$ extend the knowledge of students about various aspects of daily life of minor communities by presenting various media, works of art or literary creations, which constitute instructive-formative forms of an intercultural typology.

The basis of an intercultural educational system, in the context of keeping the authentic intercultural values, should be developed behind the boundaries of a competitive axiology. It is intended to promote through education a continuum of values, bridges between various cultures, ethnicities, religions or races which are in contact.

It is necessary for the students to be aware that the differences of various cultures. But it does not imply that they are also divergent. Nor the promotion of the system of values by which a given culture is guided discredits the combined effort proposed by other cultures. In this regard, it is recommended to highlight the symbols and the cultural elements which are common to different communities and to transform them into a foundation which ensures the integration of the sum of particularities, that are distinctive for each culture, in a system of universal values that that apply to all humanity.

In order to achieve this goal, the redesign of the curricula and disciplines in terms of a curriculum capable of reflecting the plurality of the existing cultures in society, thus resulting in a content of university study programs sized in accordance with the principles imposed by the assumption of an educational policy which aims at developing its intercultural dimension. The university must become a centre which cultivates the availability of intercultural dialogue and respect of the valuables of various cultures. Students will learn to look at cultural diversity as something normal, profitable, by becoming able to connect their national value system to the international one, thus subscribing, from early time, to the ideal of European consciousness.

By promoting through education, the openness and receptivity to the values of other cultural systems and to the universal values of humanity, is the only one able to offer the possibility of an authentic intercultural dialogue and viable connections between the various cultural models currently existing.

The awareness of the fact that cultural identity, in all its aspects, is constructed and authenticated only through substantial interactions with other cultural systems, requires increased responsibilities at the level of different educational institutions. In this sense, the university has the task of contributing through concerted and unitary activities, to the effective establishment of cultural dynamicity, by means of firmly focusing on the valued fundaments of a democracy.

An important step in this direction is to overcome the obstacles represented by language barriers. Language cannot be reduced to a set of vocabulary elements and grammatical rules, but this should represent the main way of spreading the culture.

Permeabilization of these barriers can be done by finding and using similar or common words and expressions, by turning to certain strategies which involve students in activities, which by their own nature, require a differential linguistic repertoire or based on the translation of significant literary works, with a relevant content regarding the cultural environment of the author's origin or to which he/she refers.

The activities that consist of readings from intercultural literature, artwork exhibitions can contribute to the intercultural approach or to the openings which may avail fruitful information of the folk dimension of a given culture. Furthermore, activities like this may be very well filled out with the presentation of some study cases regarding the history of 
some individual families with different cultural roots or, for example, the exceptional achievements of personalities belonging to different cultures. Trips and visits to significant places with various cultural imprints can also be carried out.

Therefore, in order to achieve an intercultural education, the learning process should break the physical boundaries of the school or to the classical period of schooling. At present, it is found that intercultural education is turning into a lifelong learning process.

It is imperative to be considered and modified, whenever possible the mentality and cultural perspectives of the elders, parents in general, being known the fact that outside the university students may be the subjects of cultural pressures which can decisively influence their correct reporting to otherness. The promotion in the informal context of some attitudes of disregard or mockery towards cultural, ethnic, religious or racial values of a certain community, can irreversibly damage at the level of students the formation of a correct intercultural attitude.

Furthermore, in order to achieve a complete intercultural education is an adequate a priori training of the teachers teaching these subjects is compulsory. It is mandatory to train the future teachers with a mentality based on respect and trust for other cultures, deconstruction of cultural, racial, ethnic or religious prejudices, thus ensuring the premises of a correct relationship with various minor communities.

Of the same importance is also the endowment of the future teachers with an informational baggage that would allow them to a logical and credible argumentation that being in the limits of another cultural perspective. Furthermore, it presents the student an axiological reference system, from a different perspective and interpretation of reality, different from one's own, but not antagonistic in relation to it. In this way, a certain axiological flexibility is possible, of an availability regarding the correct relation of the student towards the values that describe and surround cultural otherness.

The norms and principles on which intercultural education is based neither replace and nor do they substitute the specific task and role of the teaching act. Their role must lead towards a functional strategy, but also describe a methodology that allows students to naturally adapt to cultural diversity in the contemporary society.

Interculturality-centred education can act as a weapon in the fight against intolerance. Promotion of the intercultural knowledge and democratic values can be achieved by a symbiosis of school and extracurricular activities that aim for a cultural integrative behaviour. Moreover, an educational approach, in the spirit of an undeniable recognition of the values of the existing cultural differences, must be undertaken.

\section{Results}

We will highlight some of the dimensions we have followed thorough this investigation.

\subsection{Teachers' experience in the field of internationalization}

In what concerns the training or the exchange of experience abroad of the teaching staff from FSHS, over $70 \%$ of the teaching staff said they have participated in classes/trainings/exchange of experience abroad. This fact shows their intercultural experience (lower or bigger), but also their openness to new. 


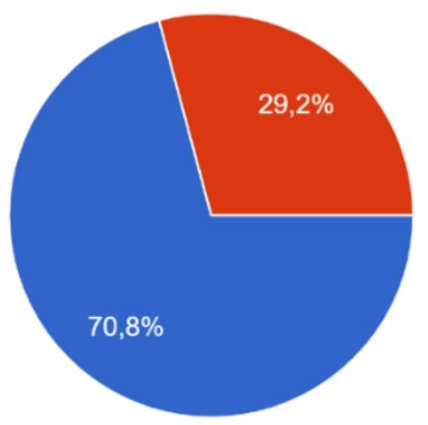

Fig. 1. The answer to question: "Have you participated at courses/ practices/ exchange programmes?".

The fact that $85,4 \%$ of teachers developed activities with Erasmus students shows that the Faculty of Socio-Human Sciences is a faculty with active international partnerships and collaborations, in which the mobility projects of teaching staff and students are very often. It is a faculty searched by international students and this fact determines the awareness of the management staff to make a module of courses taught in international languages.

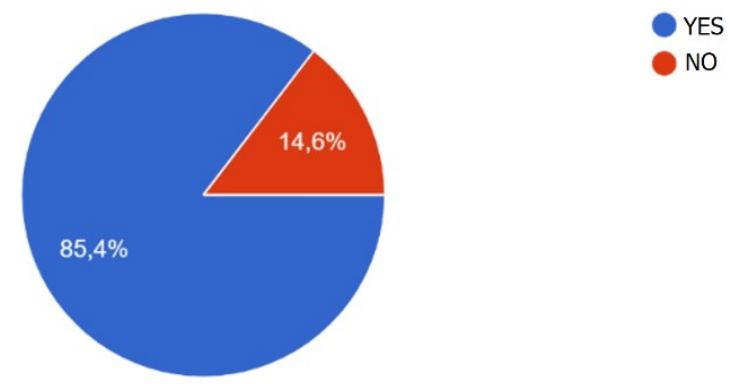

Fig. 2. The answer to question: "Did you have any ERASMUS students since you are teaching at Lucian Blaga University of Sibiu?". Source: the author.

For example, in the department of Teacher Training the most searched classes by the international students were: Psychology of Education, Pedagogy, Intercultural education, Class management, German language and methods of teaching German language, Introduction in the research of language acquisitions, Didactics in the field of language and communication, Romanian language.

In what concerns the countries of origin of the students who studied in the Faculty of Socio-Human Sciences, those are: Turkey (19), Germany (15), Spain (12), Italy (11), Greece (10), France (9), Egypt (8), Cambodia (5), Austria (4) etc.

There would have been an ideal case to have classes in English, German etc for international students.

Intercultural strategies avoid separating individuals into autonomous and impermeable cultural worlds, promoting instead comparison, dialogue and even reciprocal transformation, to make coexistence possible [13].

\subsection{Factors which have eased/laded the collaboration with foreign students}

Teachers have enumerated the following type of factors which eased the collaboration with foreign students: the interest of foreign students (the interest and participation of foreign students, common interest for attending the classes and getting the credits, the wish of Erasmus students to participate in classes, the interest of students for a certain field of 
study, taught disciplines and subjects, their wish to successfully make project/themes, curiosity and openness showed by the students for certain fields of study, their motivation to interact with colleagues and teachers from Romania:; linguistic competences, (learning foreign languages, learning English language at an academic level, learning specialized terms in English language), common elements of a different leaning systems, (teaching and scientific common fields, ability of students to adapt to the teaching system from our country, adapt in modern educational contexts, harmonization of the taught disciplines with programmes from other European faculties of profile, the necessity of classes recognition in the country of origin, lower requirements compared to the ones addressed to Romanian students).

Communication and involvement (involvement in common activities, assured mentoring by the supervisors, regulate correspondence by email), rapid facilitation of the connection with the Romanian students, offering support outside classes);, international relations (partnerships with universities from which we have students, recommendations made by the professors from foreign universities, International Relations Office, Erasmus mobility projects, work and study experience abroad, previous university collaboration through Erasmus programmes or private one).

The factors which laded the collaboration with students from abroad were: the lack of a teaching programme in English, the level of English language of the Romanian students which is very low, the lack of intercultural competences of the Romanian students; spaces for activities with foreign students; different learning systems, aspects related to interculturality.

To determine the competences (knowledge/abilities/attitudes) which a professor should have, in order to make the students aware of the importance of the interculturality, we have organized the information in three categories: knowledge, abilities, attitudes.

In what concerns the knowledge, the respondents mentioned the following facts: scientific knowledge in the field of interculturality, minimal knowledge of interculturality, knowing their own cultural identity, knowing the specific customs of other cultures, knowledge of culture and civilization etc.

Regarding abilities, the questioned teaching staff answered the following: a pragmatic approach of the cultural interferences, adapt to the culture of the country of the student, adapt to the new educational contexts, analyse and solve the problems which come up, communicate in a way which stimulates and encourages, ability of intercultural communication, project, organize and make teaching and research activities with an intercultural content, promote cultural differences.

Regarding the component attitude the respondents mentioned the following aspects: acceptance of the others, a positive attitude which determines the wish of students to join mobility projects, collaboration, respect, understanding, valorisation of diversity, curiosity towards the social and cultural background of students coming from other countries, an open attitude to new, to other cultural models, openness towards other challenges, an open interest to do a research in other countries.

Teaching staff who participated in the research claimed that many of the classes taught in the FSHS have an intercultural component.

Most of the respondents think that a training programme with a content adapted to form intercultural competences contribute to a large extent to: the internationalization of the educational institution, the visibility of the education institutions, the professional training of students, a better integration of graduate students on labour market.

Most of the respondents will be interested to participate in a training course to be able to offer students/attendees a content adapted for the formation of intercultural competences of the students. 


\section{Conclusions}

Intercultural education is a pluri-determined action, which involves: the capitalization of many human and material resources aiming to orient the young generations towards democratic values, respect, trust in the potential of every human being no matter what the ethnical, social, cultural statue. Intercultural competences of students, which includes an assembly of knowledge, competences, skills and behaviours, may be trained and developed through an intercultural curriculum projected and systematic implemented within programmes of bachelor, master and doctorate [14]. Teachers need to be aware of the role they have in the process of training and developing skills in students [15]. The hypothesis according to which the development of teaching activities in higher education in an intercultural context contributes to the formation and development of intercultural skills in students, was confirmed by the results obtained from the research conducted. Intercultural competences of the students may be formed by teachers who own these kind of competences and valorise them in educational and professional contexts so that teaching becomes a live laboratory in which democratic values based acceptance, respect to other cultures and confidence in the potential of every human being. Students with intercultural skills can contribute to the sustainability of a future society since they can integrate socially, culturally professionally without high costs and financial investments. The characteristics of their activity will be flexibility, inclusion and creativity in a sustainable intercultural society.

\section{Discussion}

The results obtained and presented following this investigation highlight the valuable psycho-pedagogical resources that exist and are capitalized in the teaching activities at the Faculty of Socio-Human Sciences within the "Lucian Blaga" University of Sibiu. However, there is the possibility of improvements and a coherent approach to formal and non-formal teaching activities organized with Romanian and foreign students. Thus, in order to streamline the process of designing and conducting university teaching activities in the paradigm of intercultural education, we have developed a training program for all faculty, and which is then intended to be extended to the university level, training program aimed at training and the development of intercultural skills in teachers and students.

\section{References}

1. C.M. Bunăiașu. Direcţii de dezvoltare a curriculumului intercultural în România, din perspectiva dimensiunii europene a educaţiei, Editura Muzeul Literaturii Române: București, Romania (2015)

2. A. Nedelcu. Fundamentele educaţiei interculturale, Polirom, Iaşi, Romania, (2008)

3. D. Mara, D. Hunyadi Eds. Școala incluzivă în societatea actuală, Editura Universitară, București, Romania (2018)

4. E. L. Mara. Development of verbal competences through reading in 11th annual International Conference of Education, Research and Innovation, Seville, Spain (2018)

5. M. Catarci, M. Fiorucci. Intercultural Education in the European Context: Theories, Experiences, Challenges in Research in Migration and Ethnic Relations Series, 1st ed.; Routledge: London, UK (2015). 
6. L.I. Cioca, R.A. Nerișanu. Enhancing Creativity: Using Visual Mnemonic Devices in the Teaching Process in Order to Develop Creativity in Students. Sustainability (2020)

7. M. Fiorucci. La mediazione culturale. Strategie per l'incontro. Armando, Roma, Italy (2000)

8. L. Ciolan. Invățarea integrată: fundamente pentru un curriculum transdisciplinar, Polirom, Iaşi, Romania (2008)

9. T. D. Walker. Să predăm ca în Finlanda: 33 de strategii simple pentru lecții pline de bună dispoziție, Editura Trei, București, Romania (2018)

10. P. Dasen, C. Perregaux, M. Rey. Educaţia interculturală. Experienţe, Politici, Strategii, Polirom, Iaşi, Romania (1999)

11. C. Cucoş. Pedagogie, Polirom, Iaşi, Romania (1996)

12. L. Ciolan. Paşi către şcoala interculturală, Editura Corint, Bucureşti, Romania (2000)

13. M. Fiorucci, F. Pinto Minerva, A. Portera. Gli alfabetti dell'intercultura, Edizioni ETS Pisa, Italy (2017)

14. D. Mara, D. Hunyadi., Eds. Învățarea interactivă și dezvoltarea gândirii critice, Editura Universitară, Bucureşti, Romania (2018)

15. J. Hattie. Învățarea vizibilă: ghid pentru profesori. Editura Trei, București, Romania (2014) 